\title{
A PWM multiplier for maximum power point estimation of a solar panel
}

\author{
José A. Carrasco ${ }^{1,2 a)}$, Francisco García de Quiros ${ }^{1,2}$, \\ Higinio Alavés ${ }^{1,2}$, and Moisés Navalón ${ }^{2}$ \\ ${ }^{1}$ Universidad Miguel Hernández de Elche, \\ Ed. Torrevaillo, Avda. Universidad sn, 03202 Elche, Spain \\ ${ }^{2}$ Embedded Instruments and Systems S.L., \\ Ed. Quorum IV, Avda. Universidad sn, 03202 Elche, Spain \\ a)jacarrasco@umh.es
}

\begin{abstract}
A simple analog multiplier for the estimation of the power yield of a solar panel may be realized with a pulse width modulator working as analog multiplier circuit of the current yield and the duty cycle of the converter used to condition the panel. Though the output of the pulse width modulator multiplication is not exactly proportional to the output power of the solar panel, its maximum follows the maximum of the power curve of the panel. This multiplier allows a complete analog implementation of the maximum power point tracker of the panel keeping, at the same time, the simplicity needed in robust electronic systems. This paper presents the working principle of the maximum power point estimator for three different power conditioners of the solar panel: a step-down, a step-up and a SEPIC.
\end{abstract}

Keywords: PWM multiplier, maximum power point estimator Classification: Power devices and circuits

\section{References}

[1] T. Esram and P. L. Chapman: "Comparison of photovoltaic array maximum power point tracking techniques,” IEEE Trans. Energ. Convers. 22 (2007) 439 (DOI: 10.1109/TEC.2006.874230).

[2] Z. Liang, et al.: "A new cost-effective analog maximum power point tracker for PV systems," IEEE Energy Conversion Congress and Exposition (ECCE) (2010) 624 (DOI: 10.1109/ECCE.2010.5617955).

[3] Y. H. Lim and D. C. Hamill: "Simple maximum power point tracker for photovoltaic arrays," Electron. Lett. 36 (2000) 997 (DOI: 10.1049/ el:20000730).

[4] W. Denzinger: "Electrical power system of globalstar," Proc. of the European Space Power Conference (1995) ESA SP-369.

[5] P. Rueda and B. Van der Werrdt: "Segregated Maximum power point tracking based on step-up regulation," Proc. of the Seventh European Space Power Conference (2005) ESA SP-589.

[6] W. Denzinger and W. Dietrich: "Generic $100 \mathrm{~V} /$ high power bus conditioning," Proc. of the Seventh European Space Power Conference (2005) ISBN: 978-9290-92900-0. 
[7] S. Oprea, et al:: Energy Harvesting and Energy Efficiency: Technology, Methods, and Applications (Springer International Publishing, 2017) 491. ISBN 978-3-319-49875-1.

[8] A. W. Carlson and C. A. Furciniti: Patent US3535657 A (1970).

[9] H. S. Chung, et al.: "A novel maximum power point tracking technique for solar panels using a sepic or cuk converter," IEEE Trans. Power Electron. 18 (2003) 717 (DOI: 10.1109/TPEL.2003.810841).

[10] N. Mohan, T. M. Undeland, and W. P. Robbins, Power Electronics: Converters, Applications, and Design, 3rd ed. ISBN: 978-0-471-22693-2.

[11] A. Garrigós, et al.: "Real time estimation of photovoltaic modules characteristics and its application to maximum power point operation," Renewable Energy 32 (2007) 1059 (DOI: 10.1016/j.renene.2006.08.004).

\section{Introduction}

Maximum Power Point Tracking (MPPT) circuits for solar arrays are subject to maximum scientific and technical interest because they considerably increase the power yield of a solar panel. The usual principle to set the working of the solar panel at its maximum power relies on the multiplication of its voltage and current yields, which are mainly dependent on the incident radiation and the environment working temperature. After this calculation, a negative feedback circuit acting over a solar panel regulator, usually implemented by a DC-DC converter, positions the operating point of the solar panel at the maximum power point over its characteristic curve. While many examples of digital techniques for tracking a solar panel maximum power point exist [1], analog techniques are less usual and commonly relay on clever techniques to implement the multiplier, such as a XNOR gate [2] or a commercial analog multiplier [3].

For very specific applications, however, it is desirable to consider simple analog circuitry to offer a high degree of simplicity and robustness and very well-known failure modes. These are the reasons for the existence and use of the Denzinger MPPT for space systems [4] based on a property of the I-V characteristic curve of the solar panel that relates the ratio between the current and the voltage of the panel with the derivative of the current with respect to the voltage; and the Rueda MMPT [5] that maximizes the current at the output of a DC-DC converter that regulates the solar array over a constant bus voltage.

Even simpler approaches exist such as approximating the MPPT of a solar panel by placing its voltage at a certain percentage (usually between 70 and $75 \%$ ) of its open circuit voltage. However, this technique does not actually place the panel over its MPPT and, worse, the circuitry has to short circuit and open the panel (to fully calculate the characteristic curve) producing disturbances and losses of the solar power.

\section{Working principle of the proposed Maximum Power Point Estimator}

The present strategy to estimate the maximum power point of a solar panel (or solar array) has been developed to extract energy from the panel to a power bus at a 
lower, bigger, or equal voltages and therefore covers a general arrangement used in autonomous systems, such as telecommunications and Earth observation satellites [6], and even smaller spacecraft platforms [7]. The power bus fed by the solar panel does not need to be precisely regulated, the only requirement for it is having a voltage that changes slowly with time (as in battery bus for example) in order to not interfere with the MPPT tracking circuitry, and thus this strategy is general and may be readily used in non-regulated buses as well as regulated ones.

The working principle of the MPPT relies on a pulse width modulator multiplier, followed by low pass filter and a peak detector. The use of a PWM modulator as a multiplier was patented in 1967 [8] and since then we may find it within many different electronic circuits. However, it has not yet been applied in the implementation of the multiplier of a maximum power point estimator as described in this paper.

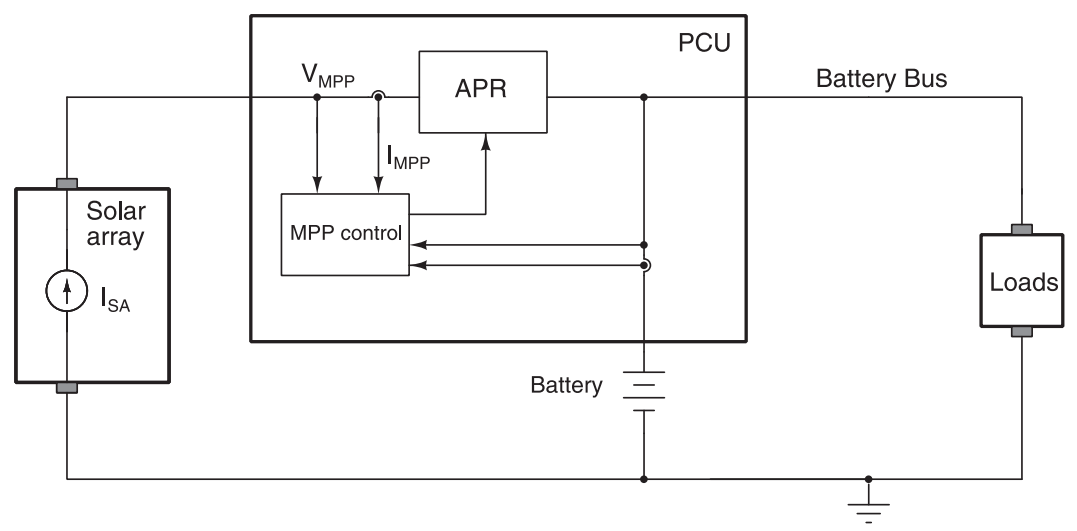

Fig. 1. An Array Power Regulator (APR) with Maximum Power Point (MPP) estimation and control.

A typical implementation of the MPPT described in this paper is shown in Fig. 1. An Array Power Regulator (APR) supplies a battery (to which one or several loads are connected) that maintains constant its output voltage and receives feedback from a MPP control box, that measures the voltage and current from the panel, multiplies them, and keeps track of its maximum. Besides, the MPP control box within this schema, checks out the charge state of the battery by sensing its voltage and current. Depending on the designed ratio between the solar panel and bus voltage, the APR may be implemented by a step-down (Buck type), step-up (Boost type), or step-up/step-down (such as the SEPIC regulator).

Fig. 2 shows the possible variation in solar array voltage when implemented by triple junction GaAs cells (such as Azurspace 3G28C) normalized by the factor N, which relates the ratio of solar panel cells over battery cells when the APR is implemented by a step-down regulator. From this figure we can extract that the MPP voltage of a high performance solar array spans from $6.7 \mathrm{~V}$ to $7.5 \mathrm{~V}$ (multiplied by $3 \cdot \mathrm{N}$ ) when the irradiances go from 1 sol to half that value and the temperatures from $-20^{\circ} \mathrm{C}$ to $+60^{\circ} \mathrm{C}$, which are usual values for Earth and space environments. 


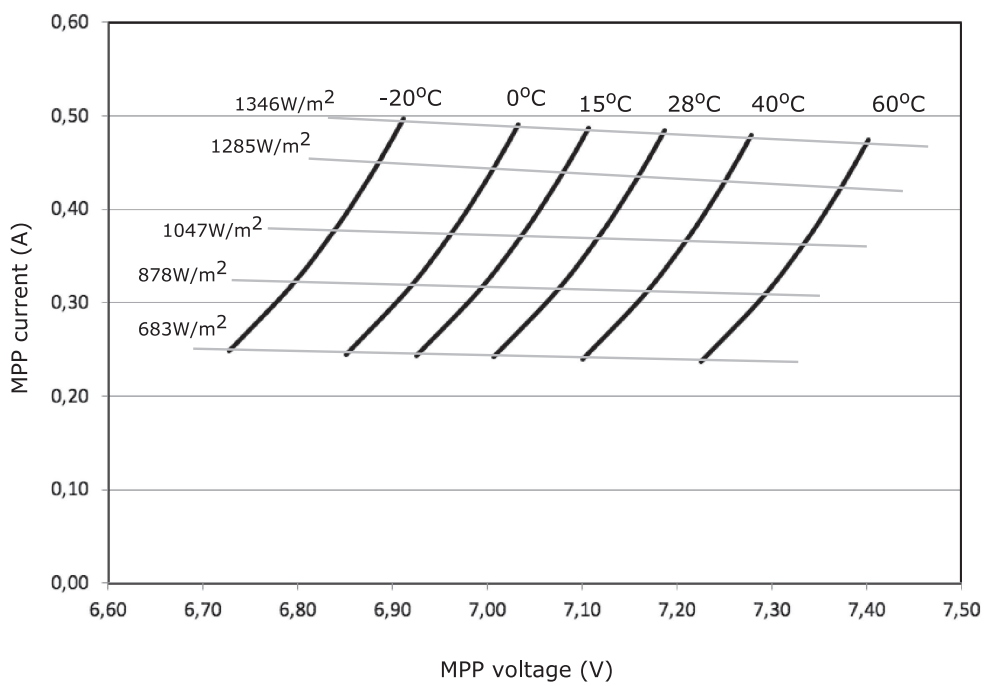

Fig. 2. Maximum power pint values for a solar array and its dependence with temperature and irradiance normalized to $3 \cdot \mathrm{N}$, where $3 \cdot \mathrm{N}$ is the number of cells in the array with respect to battery cells when the APR is a step-down regulator.

Fig. 3 shows the implementation of the PWM multiplier and the MPP estimator based on the step-down (Buck) converter. Although the DC-DC converter in this figure is implemented by a step-down regulator, a step-up or SEPIC converter may be valid for the described principle as well. Table I shows the proposed converter duty cycles for these three cases, whose implementation depends on the number of battery cells with respect to that of the solar panel.

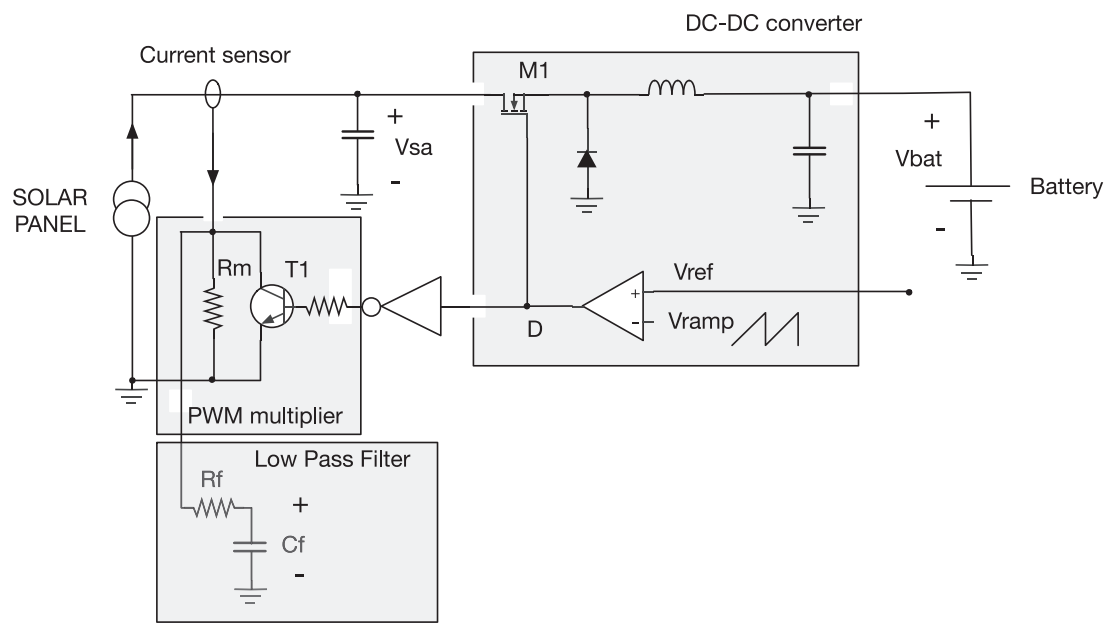

Fig. 3. The PWM multiplier circuit as an estimator of a panel MPP.

Regarding Fig. 3, the current sensor measures the current provided by the solar panel and, after amplification, is converted to voltage by the resistor Rm and chopped by the transistor $\mathrm{T} 1$, which is linked to the duty cycle of the converter. If we consider the equation (1) of the current yield of the solar panel with no parasitic components for simplicity [9].

$$
I_{s a}=I_{s c}-I_{r} \cdot\left(e^{\alpha \cdot \frac{V_{b a t}}{D}}-1\right)
$$


Table I. APR selection for battery voltages above, below or equal to solar array MPP.

\begin{tabular}{|c|c|c|c|c|}
\hline $\begin{array}{c}\text { Voltage of solar panel } \\
\text { normalized to } 3 * \mathrm{~N}\end{array}$ & $\begin{array}{c}\text { Voltage of battery } \\
\text { normalized to } \\
\text { number of cells }\end{array}$ & $\begin{array}{c}\text { Number of } \\
\text { battery cells }\end{array}$ & Converter type & $\begin{array}{c}\text { Duty cycle variation } \\
(\%)\end{array}$ \\
\hline from $6.7 \mathrm{~V}$ to $7.4 \mathrm{~V}$ & from $3.5 \mathrm{~V}$ to $4.1 \mathrm{~V}$ & $\mathrm{~N}$ & BUCK & from $47 \%$ to $61 \%$ \\
\hline from $6.7 \mathrm{~V}$ to $7.4 \mathrm{~V}$ & from $10.5 \mathrm{~V}$ to $12.3 \mathrm{~V}$ & $3 * \mathrm{~N}$ & BOOST & from $30 \%$ to $45 \%$ \\
\hline from $6.7 \mathrm{~V}$ to $7.4 \mathrm{~V}$ & from $7.0 \mathrm{~V}$ to $8.2 \mathrm{~V}$ & $2 * \mathrm{~N}$ & SEPIC & from $49 \%$ to $54 \%$ \\
\hline
\end{tabular}

Where $I_{\mathrm{sa}}$ is the current of the solar panel, $\mathrm{I}_{\mathrm{sc}}$, its short circuit current, $\mathrm{I}_{\mathrm{r}}$ its dark current and $\alpha$ a parameter that depends on the solar cells. The simplest case for the APR is to consider it implemented by a step-up (Boost type) converter and therefore the ratio between the solar panel voltage (i.e. its input voltage), $\mathrm{V}_{\mathrm{sa}}$, and the bus (battery) voltage (i.e. its output voltage), $\mathrm{V}_{\text {bat }}$, is given by (2), where $\mathrm{D}$ is the duty cycle of the converter.

$$
\frac{V_{b a t}}{V_{s a}}=\frac{1}{1-D}
$$

The power yield of the solar panel, by combining (1) and (2) results, is given in (3).

$$
P_{s a}=V_{s a} \cdot I_{s a}=(1-D) \cdot V_{b a t} \cdot\left[I_{s c}-I_{r} \cdot\left(e^{\alpha \cdot \frac{V_{b a t}}{D}}-1\right)\right]
$$

The averaged voltage at $R_{m}$, measured at $C_{f}$, is given in (4) by taken into account that the driver of transistor $\mathrm{T} 1$ is synchronized with the inverted duty cycle of the step-up regulator, where $\mathrm{G}$ is the gain of the current sensor.

$$
V_{C f}=R_{m} \cdot G \cdot I_{s a} \cdot(1-D)=(1-D) \cdot R_{m} \cdot G \cdot\left[I_{s c}-I_{r} \cdot\left(e^{\alpha \cdot \frac{V_{b a t}}{D}}-1\right)\right]
$$

As may be seen from (3) and (4) both expressions, though not equal, have its maxima in the same position since Vbat, $\mathrm{G}$ and $\mathrm{Rm}$ are constants (at a given working point) and both expressions depend on the product of the complementary of the duty cycle and the solar panel current. Therefore, the voltage at $\mathrm{C}_{\mathrm{f}}$, obtained through a PWM multiplication may be used to estimate the MPP of the solar panel.

For the step-down (Buck type) APR, the ratio between $\mathrm{V}_{\text {sa }}$ and $\mathrm{V}_{\text {bat }}$ is given by (5) and the power yield of the solar panel by (6).

$$
\begin{gathered}
\frac{V_{b a t}}{V_{s a}}=D \\
P_{s a}=\frac{V_{b a t}}{D} \cdot I_{s a}=\frac{V_{b a t}}{D} \cdot\left[I_{s c}-I_{r} \cdot\left(e^{\alpha \cdot \frac{V_{b a t}}{D}}-1\right)\right]
\end{gathered}
$$

By synchronizing the transistor T1 (see Fig. 3) with the complementary of the duty cycle of the step-down converter to get at $\mathrm{C}_{\mathrm{f}}$ the voltage given by (4) and considering the approximation (7), which has a maximum error of $1.2 \%$ when the duty cycle D is within the range given in Table I for the Buck converter.

$$
(1-D) \approx \frac{0.245}{D} \text { for } D \in[0.47,0.61] \text { with an error less than } 1.2 \%
$$

By introducing (7) in (6) we get (8). Again (4) and (8) are not equal but they have its maxima is the same point over the characteristic curve of the solar array. To probe that (8) approximates correctly equation (6) we provide Fig. 4 that shows 
the duty cycle difference between the exact MPP given by (6) and the approximate (estimated) one given by (8) at different irradiances and temperatures for different battery voltages. As we may see, at a given MPP defined by the battery voltage and the solar array conditions, the difference (i.e. error) in duty cycles is less than $1 \%$ which results in a power error of less than $2 \%$ as shown in Fig. 5 . These two figures show different curves for the values of irradiance and temperature extracted from Fig. 2.

$$
P_{s a}=\frac{(1-D)}{0.245} \cdot V_{b a t} \cdot I_{s a} \approx \frac{(1-D)}{0.245} \cdot V_{b a t} \cdot\left[I_{s c}-I_{r} \cdot\left(e^{\alpha \cdot \frac{V_{b a t}}{D}}-1\right)\right]
$$

From this reasoning we conclude that the PWM multiplier can be used as MPP estimator of a solar array and therefore the voltage at $\mathrm{C}_{\mathrm{f}}$, in Fig. 3, may be used to estimate the MPP of the panel when conditioned with a step-down regulator.

For the SEPIC (Buck-Boost) converter [9], we follow the same approach than for the Buck converter. Being the combination of a Buck and a Boost, the power yield of the solar array is given by (9) where we have introduced the approximation (10) that is verified within the duty cycle ranges provided in Table I. As may be seen the right part of (9) has the maximum in the same place as (4), which results in an MPP estimated approximately equal to the actual MPP as Fig. 6 and Fig. 7 show.

The approximation in error for the SEPIC in (10) is not as low as the one for the Buck in (7), but it results in a very small difference in the duty cycle of the estimated MPP and the ideal MPP, which as shown in Fig. 6 is less than 1.2\%. Nevertheless, for the SEPIC converter small variations in duty cycle are translated in big variations in the ratio between the input and output voltages and the PWM estimator for D produces power yield errors as big as $10 \%$ for the conditions reflected in Fig. 2, see Fig. 7.

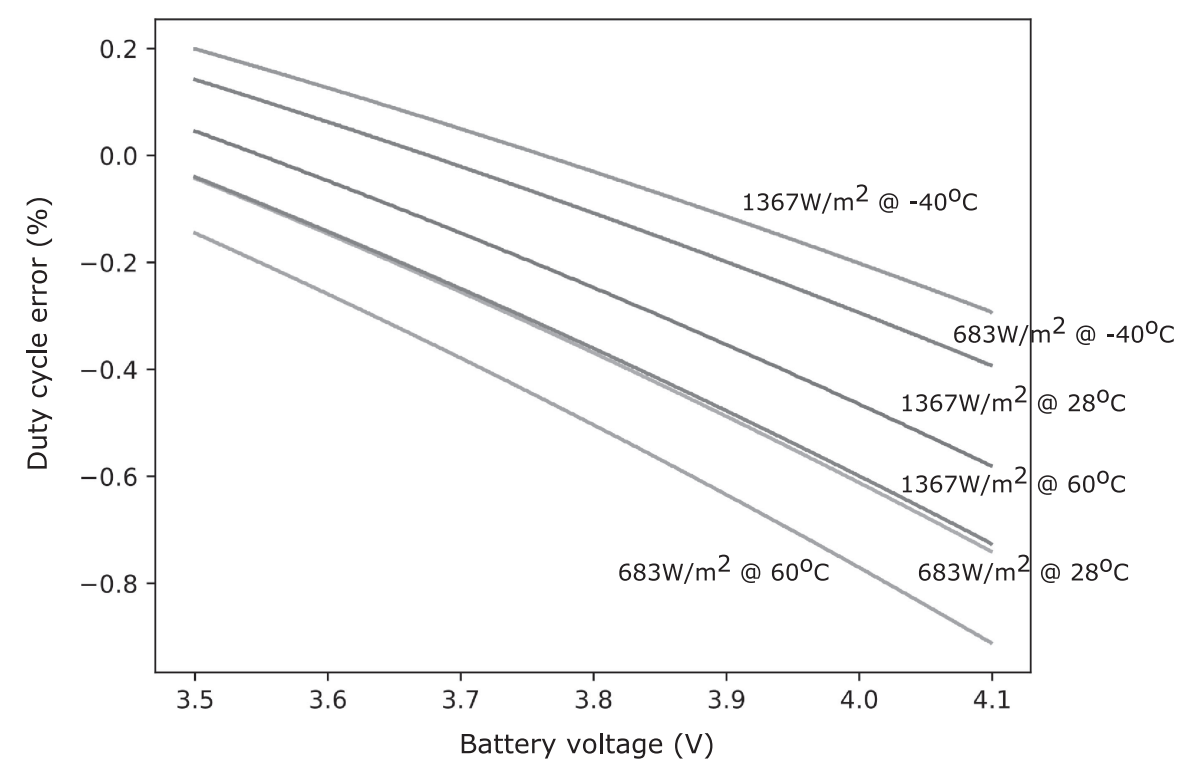

Fig. 4. The differences (error) in duty cycle of the Buck APR when the PWM multiplier is used to estimate the MPP of a solar panel for it working under extreme irradiances and temperatures for different battery voltages. 


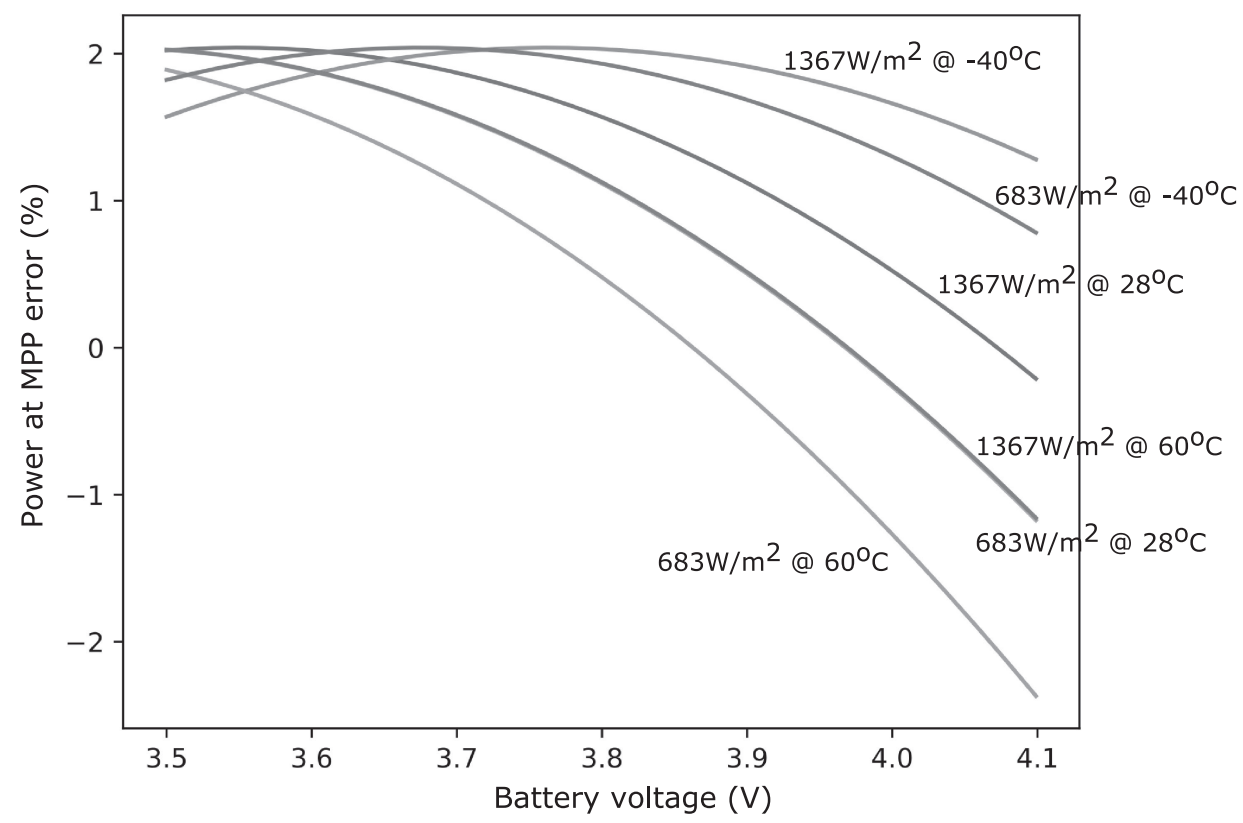

Fig. 5. The power error of the solar array working at MPP for extreme irradiances and temperatures with the Buck APR and PWM multiplier as estimator.

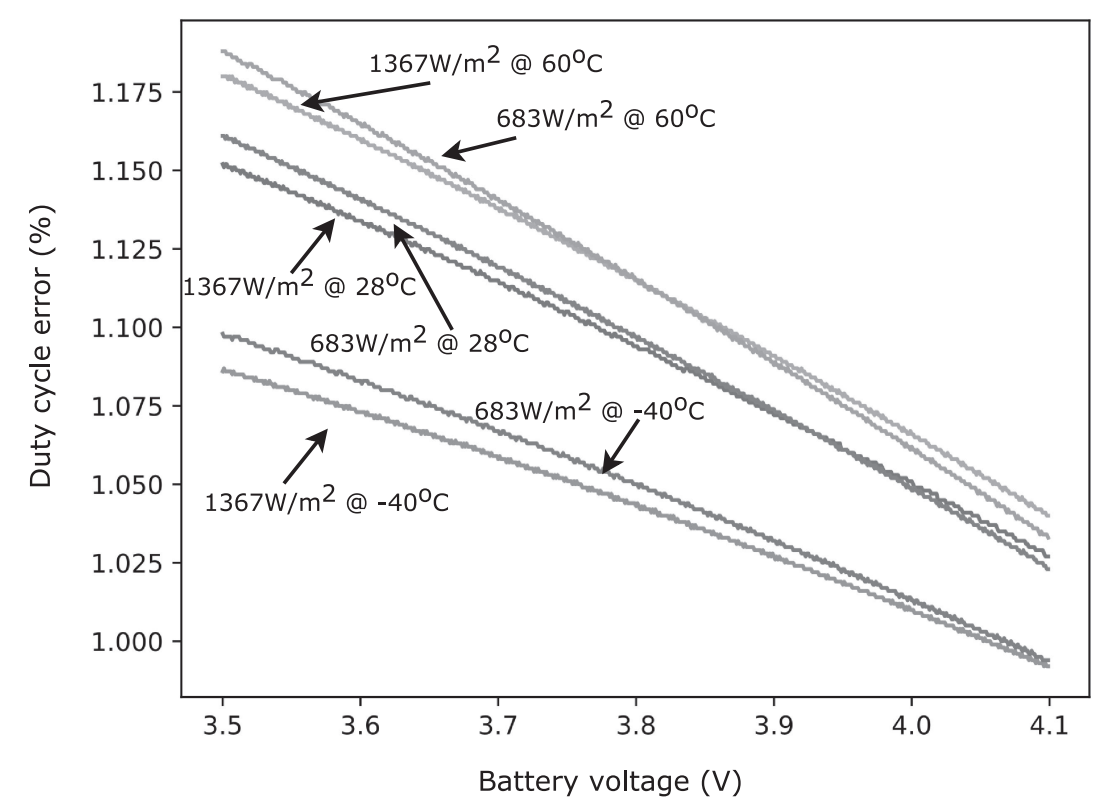

Fig. 6. The duty cycle error for the SEPIC converter when using a PWM multiplier as MPP estimator for the irradiances and temperatures in Fig. 2.

$$
\begin{aligned}
& P_{s a}=\frac{(1-D)}{D} \cdot V_{b a t} \cdot I_{s a} \approx 1.9 \cdot(1-D) \cdot V_{b a t} \cdot\left[I_{s c}-I_{r} \cdot\left(e^{\alpha \cdot \frac{V_{b a t}}{D}}-1\right)\right] \\
& \frac{(1-D)}{D}=1.9 \cdot(1-D) \quad \text { for } D \in[0.49,0.54] \text { with an error less than } 4 \%
\end{aligned}
$$

\section{Experimental results}

An MPP estimator has been built by implementing the circuit in Fig. 3 with a solar panel made out of three Azurspace triple junction 3G28C cells in series (providing 


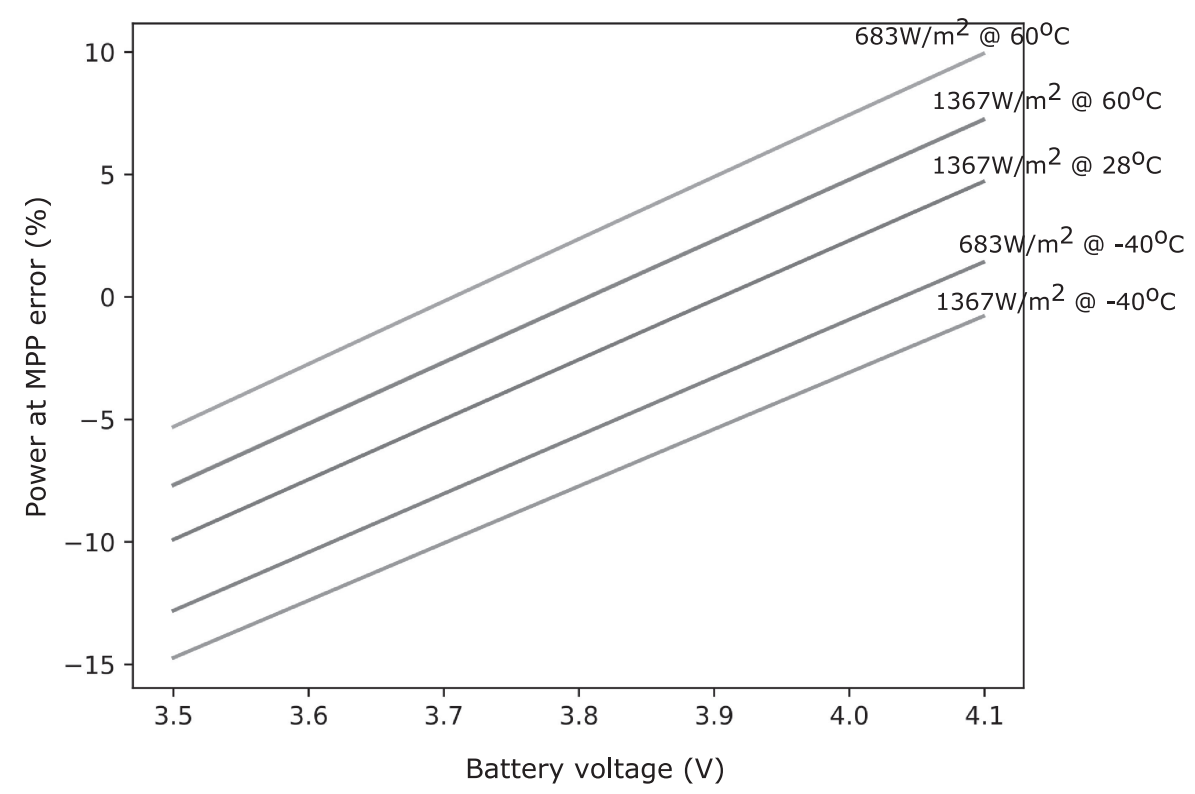

Fig. 7. The power error of the solar array working at MPP for irradiances and temperatures given in Fig. 2 for the SEPIC APR and PWM multiplier as estimator.

approximately 7.1 V and 3.5 W at its ideal MPP) and using one SAFT MP144350 (4.1 V at full charge) Li-Ion cell. The APR is a Buck designed using a standard procedure [10] working at $250 \mathrm{kHz}$. The current sensor has a gain of 10, T1 is implemented by a $2 \mathrm{n} 2222$ transistor and $\mathrm{R}_{\mathrm{m}}$ and $\mathrm{C}_{\mathrm{f}}$ provide a filtering bandwidth of $2 \mathrm{kHz}$ approximately.

We present results that use a laboratory light table with a capability of providing a maximum of 1 Sol. Different solar panel curves for different irradiances are obtained by tilting the solar cell with respect to the light incident angle and sweeping the duty cycle of the APR converter over a constant bus (battery) voltage.

It is possible to obtain an approximation of the solar panel characteristic curve by measuring several working points at a constant irradiance and following the procedure described in [11], which provides a very good estimation of both the characteristic curve and the position of the maximum power point. Four (I, V) coordinates are usually enough to obtain a very good approximation. As an example, estimated curves for three irradiations are presented in Fig. 8 obtained from the measured points marked as crosses, that result by sweeping the duty cycle of the Buck under constant solar array illumination and provides, by calculation, the MPP based on values for $I_{s c}, I_{r}$ and $\alpha$ that make the curve (1) fit through these

Table II. Estimated and measured MPP in the experimental setup. 


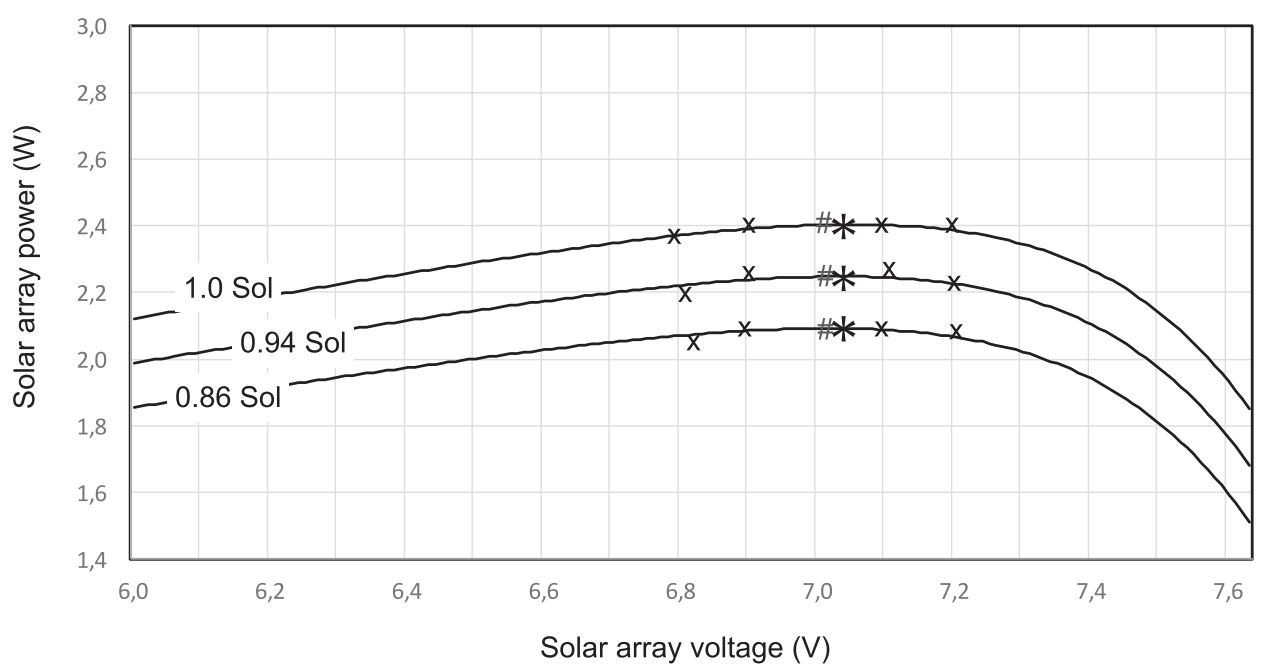

Fig. 8. Steady-state condition of the experimental measurement of the MPP circuit. The " $\mathrm{x}$ " are measured points of the characteristic curve used to theoretically estimate the curve, in solid line; the hash is the position of the MPP as estimated by the Buck APR and the asterisk the actual MPP position as calculated from current and voltage measurements.

points with minimum error. The MPP for each curve is, as well, verified by actual $\mathrm{I}_{\mathrm{SA}}$ and $\mathrm{V}_{\mathrm{SA}}$ measurements.

The MPP estimated by the PWM multiplier is given by the maximum voltage value measured at the output of the PWM multiplier $\left(\mathrm{C}_{\mathrm{f}}\right.$ in Fig. 3$)$ when sweeping the Buck duty cycle and is marked with a hash character in Fig. 8 over the characteristic curve of the solar array. This estimated value is compared with the actual MPP value, represented in Fig. 8 with an asterisk sign, obtained with the maximum value of the direct multiplication of the array voltage and current, which greatly coincides with the calculated value given by the solar array approximation as provided by [11].

As may be seen in Table II the experimental value provided by the estimator and the measured value (after actual current and voltage solar panel figures) differ in less than $2 \%$, thus verifying our theoretical approximations.

\section{Conclusion}

A multiplier based on a Pulse Width Modulator has been used to calculated the maximum power yield by a solar panel by estimating its position by using a stepdown, step-up and SEPIC (step-down step-up) DC-DC converter. Although the output of the multiplier is not proportional to the energy output of the panel, it may be shown that their maxima approximately coincide, and therefore this principle may be used as a maximum power point estimator to implement a maximum power point tracker. An experimental setup has been developed to verify operation principle based on a DC-DC step-down converter.

\section{Acknowledgments}

The authors are grateful to the company Embedded Instruments and Systems for its support in building and testing the working prototype presented in this paper. 